\title{
The Practicality of Top-root Ratio in Nursery Stock Characterization
}

by

\author{
G.D. Racey, C. Glerum and R.E. Hutchison 1
}

\begin{abstract}
Top-root ratios (T/R) form a non-normal frequency distribution which is positively skewed or skewed to the right, creating a bias in the estimate of a sample mean. T/R's determined by volume displacement give larger estimates than those determined by oven-dry weight. This difference increases with the size and T/R of the tree. Top length, stem diameter, top volume and root volume are all better indicators of nursery stock quality and potential growth performance than T/R. As top-root ratio is difficult to interpret or use in an objective manner it is of little value in nursery stock evaluation.
\end{abstract}

\section{Résumé}

Le rapport de volume tige-racine (T/R) donne une distribution de fréquence anormale à asymétrie positive ou de droite, qui cause un biais dans l'estimé de la moyenne simple.

Le rapport T/R déterminé par déplacement de volume donne des estimés plus grands que ceux qui sont déterminés par le poids sec. Cette différence augmente avec la dimension et le rapport T/R. La longueur de la tige, le diamètre du tronc, le volume de la tige et le volume racinaire sont tous de meilleurs indicateurs de la qualité du stock en pépinière et du potentiel de croissance que ne l'est le T/R. Comme le rapport tige/racine est difficile à interprèter et à déterminer, il est de peu de valeur dans l'étude des stocks en pépinière.

\section{Introduction}

The top-root ratio ( $T / R)$ of forest tree nursery stock has been used for many years to determine whether or not the stock is balanced, as a reflection of nursery practice (Armson and Carman 1961: Mullin 1976). This balance between top and root may also be a temporary phenomenon reflecting provenance and length of growing season (Cannell and Willett 1976). Many tree planters interpret a large root in relation to the top as being a feature beneficial to the survival and growth of stock during the period of stress after outplanting.

Traditionally, a range of $T / R$ values have been used to characterize stock (Armson and Carman 1961; Reese and Sadreika 1979). However, Mullin and Christl (1981, 1982) have recommended culling guidelines for nursery stock based on maximum $T / R$ values and minimum values of other morphological characteristics such as top length, stem diameter and root volume. On the other hand, Edgren (1977) found that $T / R$ had little or no value as an estimator of seedling quality. The practicality of $T / R$ as a criterion for culling or grading is controversial and needs to be examined. This paper examines 3 aspects of the practical use of $T / R$ :

Midhurst Research Unit, Ontario Tree Improvement and Forest Biomass Institute, Ministry of Natural Resources, Midhurst. Ontario. LOL 1 XO
1. Four methods of calculating $T / R$ are examined for bias using red pine

2. $T / R$ determination by oven-dry weight is compared with $T / R$ by volume displacement using red pine

3. $T / R$ is compared with other morphological measurements as indicators of stock quality of white spruce and white pine nursery stock.

\section{Methods}

In the fall of 1981,200 bed-run $2+0$ and $1+2$ red pine (seed source site region 6E (Hills 1969)) were lifted at the Midhurst $\left(44^{\circ} 30^{\prime} \mathrm{N}, 79^{\circ} 45^{\prime} \mathrm{W}\right)$ tree nursery. The $\mathrm{T} / \mathrm{R}$ was determined for each tree by both the volume displacement (Burdett 1979; Glerum and Boufford 1979) and oven-dry weight methods. Data were examined for normality and degree of agreement among four methods of estimating the population top-root ratio (also referred to as average and measure of central tendency). The four methods of estimation were:

1. arithmetic mean $\overline{T / R}=\frac{\sum_{i=1}^{n}\left(T_{i} / R_{i}\right)}{n}$ 
2. arithmetic mean following logarithmic transformation

$$
\overline{T / R}=\text { antilog }\left(\sum_{i=1}^{n} \ln \left(T_{i} / R_{i}\right) / n\right)
$$

3. median

$$
\overline{T / R}=\begin{aligned}
& \text { midpoint of all values of the top- } \\
& \text { root ratio }
\end{aligned}
$$

4. ratio of the totals

$$
\overline{T / R}=\frac{\sum_{i=1}^{n} T_{i}}{\sum_{i=1}^{n} R_{i}}
$$

where $T_{\text {i }}=$ top weight or volume where $R_{i}=$ root weight or volume where $n=$ number of trees

Two other methods not presented in this paper, but which would probably be suitable are the harmonic mean and the square root transformation for small numbers.

The remainder of this paper is based upon data from outplanting experiments initiated by Dr. R.E. Mullin and some of the data have already been described (Mullin and Christ 1981, 1982). These experiments were designed to correlate pre-planting morphological characteristics of $3+0,2+2$ and $1 \frac{1}{2}+1 \frac{1}{2}$ white spruce and $3+0$ and $2+2$ white pine nursery stock with height growth and survival after outplanting. The lifting and outplanting methodologies are well documented in the above papers. The data obtained were:

i) top length, root collar to base of terminal bud

ii) stem diameter at about $1.5 \mathrm{~cm}$ above root collar

iii) top-root ratio, measured by top and root water volume displacement.

The relative value of $T / R$ as a predictor of outplanting success was evaluated by comparing the $R$-square value $\left(R^{2}\right)$ of the regression of fifth-year heights on each morphological characteristic of the outplanted trees. Fifth-year height is a good measure of outplanting success and in most cases, the stand can be considered established at this time. In this comparison the natural logarithm of each $T / R$ was used in calculating $R^{2}$ values instead of the untransformed values.

\section{Results and Discussion}

The frequency distribution of the T/R of $1+2$ red pine stock was positively skewed (Fig. 1) whereas the $2+0$ stock distribution was not skewed. For $2+0$ stock the volume and ovendry methods of determination produced similar frequency distributions, but with the $1+2$ stock the distribution by the volume method is less compact (Coeff. of variation $=26.5$ vs 21.1) and is shifted $(P<.05)$ to the right (Table 1$)$. The $T / R$ of the $1+2$
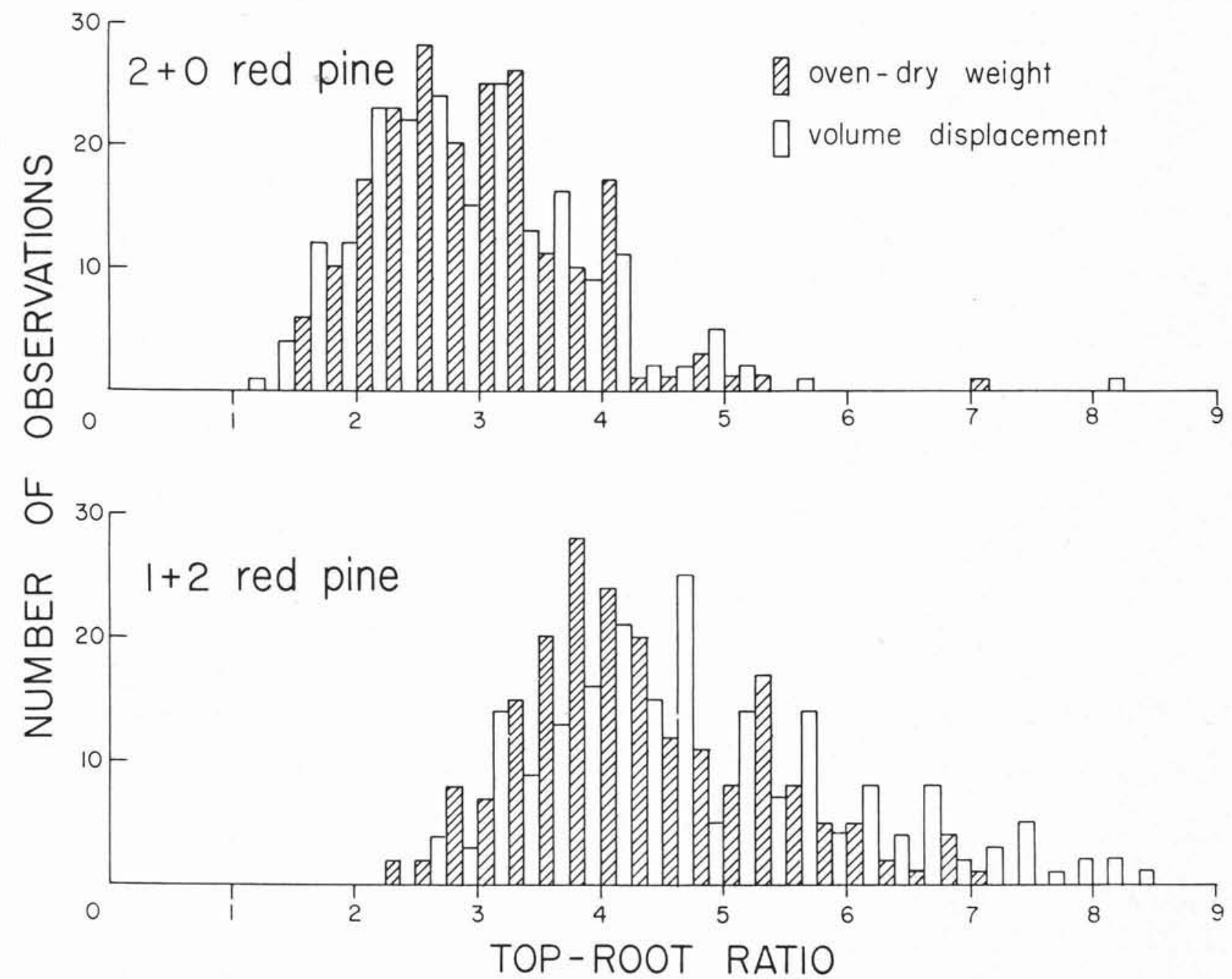

Figure 1. Frequency distribution of observed top-root ratio of $2+0$ and $1+2$ red pine from Midhurst as determined by volume displacement and oven-dry weight methods. 
Table 1. Average values of the frequency distributions of 200 observations for each of two top-root ratio determination methods and two age classes of red pine. These values were calculated using the logarithmic transformation.

\begin{tabular}{lccc}
\hline & $\begin{array}{c}\text { Volume } \\
\text { displacement } \\
(\mathbf{m l})\end{array}$ & $\begin{array}{c}\text { Oven-dry } \\
\text { weight } \\
\mathbf{( g )}\end{array}$ & \\
\hline $\begin{array}{c}\text { Age-class } \\
1+2\end{array}$ & 4.59 & 4.28 & $\cdot$ \\
$2+0$ & 2.75 & 2.97 & NS \\
& $\cdots$ & $\cdots$ & \\
\hline
\end{tabular}

NS $=$ not significant

- = significant at $5 \%$ leve

$\cdots=$ significant at $1 \%$ level

stock was significantly $(P<.001)$ larger than for the $2+0$ stock.

Methods of calculation Frequently, in the estimation of ratios, estimators that are otherwise convenient and suitable are found to be biased (Cochran 1977). This is a result of both numerator and denominator varying independently from sample to sample. This is true with red pine where a correlation of only . 45 exists between top and root volume.

Top-root ratios in this sample form a non-symmetric or skewed distribution indicating that the data are not normally distributed, reducing the effectiveness of the arithmetic mean as a measure of central tendency. Alternative methods are non-parametric such as the median (Hollander and Wolfe 1973) or the logarithmic transformation (Steel and Torrie 1960). When using the logarithmic transformation, the $T / R$ is replaced by the natural logarithm (In) of the $T / R$. The transformation procedure, although much more difficult and timeconsuming by calculator, is often chosen over the median because of unfamiliarity with or lack of confidence in nonparametric methods. The last alternative, unbiased in its estimate of the average for large samples (Cochran 1977), is to divide the total top volume by the total root volume.

A statistical comparison among the averages presented in Table 2 would be of little value due to the different methods of calculation. However, there was no difference in estimating the average of the $2+0$ sample by using either the arithmetic mean or the ratio of the top and root totals (Table 2). This applied to both the volume and oven-dry methods of determination. The logarithmic transformation and median provided estimates of the average which were lower than the preceding two. In the $1+2$ sample, where the distributions were significantly $(P<.05)$ skewed, the arithmetic mean was appreciably larger than the other three estimates for both methods. These differences in estimates of the average will increase with the degree of skewness of the distribution. A discrepancy of this type is known as a positive bias; a situation where the estimate of the population average is larger than warranted. This type of bias can create a major problem in comparing $T / R$ of various samples of trees

Oven-dry weight vs volume displacement The T/R is commonly detrmined from top and root oven-dry weights. However, the non-destructive volume displacement method (Glerum and Boufford 1979; Burdett 1979) permits stock to be outplanted following measurement allowing field performance to be correlated to pre-planting morphological characteristics.

In a comparison of $T / R$ determination by oven-dry weight and volume displacement (Glerum and Boufford 1979), it was concluded that $T / R$ determined by the volume method is consistently higher than that determined by oven-dry weights and that the relationship between the two methods was linear. In this study the difference between methods was larger with $1+2$ stock than with $2+0$ stock. Therefore, we tested the hypothesis that the difference between the two methods increased with the magnitude of the top-root ratio. This
Table 2. Average values of the frequency distribution for two top-root ratio determination methods, two age-classes and four calculation methods for red pine.

\begin{tabular}{lcc}
\hline & $\begin{array}{c}\text { Volume } \\
\text { displacement } \\
(\mathbf{m l})\end{array}$ & $\begin{array}{c}\text { Oven-dry } \\
\text { weight } \\
\mathbf{( g )}\end{array}$ \\
\hline Age-class 2+0 & & \\
Arithmetic mean & 2.89 & 3.03 \\
In transformation* & 2.75 & 2.97 \\
Median & 2.75 & 2.97 \\
T/R* & 2.89 & 3.07 \\
Age-class 1+2 & & \\
arithmetic mean & 4.75 & 4.38 \\
In transformation & 4.59 & 4.28 \\
Median & 4.60 & 4.21 \\
T/R & 4.58 & 4.27 \\
\hline
\end{tabular}

- transformation by natural logarithms

*ratio of top total to root total

regression was significant $(P<.001)$. This implies that at low $T / R$ the volume and dry-weight methods give similar values but differences between estimates become increasingly greater as T/R increases, probably due to differences in the density of the tops and roots (Glerum and Boufford 1979). Also, this relationship appears linear (Fig. 2) over small ranges of $T / R$ but may become non-linear when including large values of $T / R$ (exceeding $5: 1$ ).

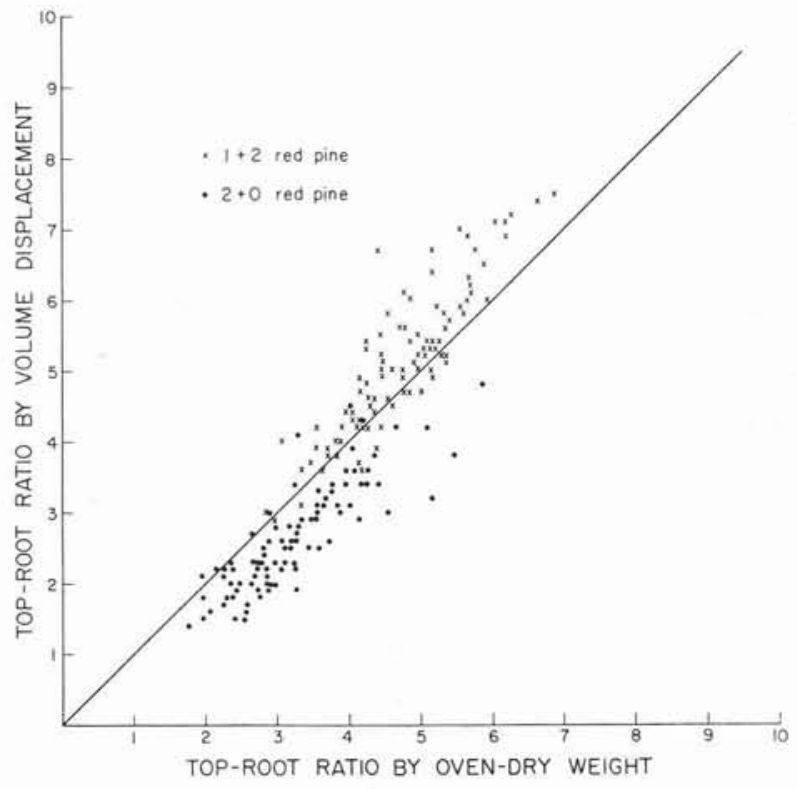

Figure 2. Scatterplot of top-root ratio estimates as determined by oven-dry weight and volume displacement for two age classes of red pine. The diagonal line represents a $1: 1$ relationship.

Table 3. Mean values for 5 morphological characteristics of three age-classes of white spruce at time of outplanting in 1974 or 1977.

\begin{tabular}{lcccc}
\hline Parameter & $\mathbf{1 9 7 7}$ & $\mathbf{1 9 7 7}$ & $\mathbf{1 9 7 4}$ & $\mathbf{1 9 7 4}$ \\
\hline Top length, $\mathrm{cm}$ & $\mathbf{1 1 / 2 + \mathbf { 1 } / \mathbf { 2 }}$ & $\mathbf{3 + 0}$ & $\mathbf{3 + 0}$ & $\mathbf{2 + 2}$ \\
Stem diameter, $\mathrm{cm}$ & 33.8 & 26.5 & 20.6 & 25.1 \\
Root volume, $\mathrm{ml}$ & 0.69 & 0.42 & 0.43 & 0.63 \\
Top volume, $\mathrm{ml}$ & 15.7 & 5.1 & 4.0 & 11.1 \\
Top-root ratio & 39.9 & 15.7 & 10.2 & 22.9 \\
& 2.44 & 3.02 & 2.56 & 2.08 \\
\hline
\end{tabular}


Table 4. R-square values for each of the morphological measurements of white spruce ( $\mathrm{Sw}$ ) and white pine (Pw) as predictors of fifth-year height of each individual tree.

\begin{tabular}{|c|c|c|c|c|c|c|}
\hline \multirow[b]{2}{*}{ Characteristics } & \multicolumn{2}{|c|}{1974} & \multicolumn{2}{|c|}{1975} & \multicolumn{2}{|c|}{1977} \\
\hline & $\begin{array}{l}\text { Sw } 3+0 \\
n=241\end{array}$ & $\begin{array}{l}\text { Sw } 2+2 \\
n=250\end{array}$ & $\begin{array}{l}\text { Pw } 3+0^{1} \\
n=400\end{array}$ & $\begin{array}{c}\text { Pw 2+2 } \\
n=399\end{array}$ & $\begin{array}{c}\text { Sw } 1 \frac{1 / 2}{2}+1 \frac{1}{2} \\
n=490\end{array}$ & $\begin{array}{l}\text { Sw } 3+0 \\
n=487\end{array}$ \\
\hline Top length, cm & 0.10 & 0.26 & 0.23 & 0.27 & 0.31 & 0.18 \\
\hline Stem diameter, cm & 0.18 & 0.20 & 0.25 & 0.27 & 0.31 & 0.24 \\
\hline Top volume, $\mathrm{ml}$ & 0.21 & 0.22 & 0.23 & 0.27 & 0.33 & 0.24 \\
\hline Root volume, $\mathrm{ml}$ & 0.18 & 0.19 & 0.22 & 0.25 & 0.31 & 0.26 \\
\hline In of top-root ratio & 0.00 & 0.00 & 0.09 & 0.12 & 0.02 & 0.06 \\
\hline Average fifth-year height $(\mathrm{cm})$ & 87 & 107 & 101 & 118 & 129 & 103 \\
\hline
\end{tabular}

effect of 5 different lifts removed by analysis of covariance

Evaluating stock quality The size of nursery stock may vary considerably from one year to the next due to seed quality, planting density, weather conditions and nursery practice. For instance, the Midhurst spruce stock used by Mullin (1981) in 1974 was significantly smaller than that used in the 1977 planting (Table 3). The transplanted stock $\left(1 \frac{1}{2}+1 \frac{1}{2}\right.$ and $2+2$ ) had consistently larger fifth-year heights than $3+0$ seedling stock. Top length, stem diameter, top volume and root volume were all reasonably good predictors of fifth-year height ( $T$ able 4 ) but $T / R$ demonstrated a poor relationship to outplanting performance of individual trees. At best, the T/R for $2+2$ white pine accounted for 12 percent of the variation of fifth-year heights among individuals. Therefore, under the conditions of these trials T/R was an unreliable method for evaluating stock quality. This observation was also noted by Mullin and Svaton (1972) and Edgren (1977). These R2 values (Table 4) are much lower than those reported by Mullin and Christl $(1981,1982)$ because individual tree measurements were used rather than group means. One must assume a large amount of variation between individual trees is due to physiological or genetic rather than morphological variation.

Top-root ratio alone does not reflect, on an objective basis, the balance between top and root needed for optimum field performance. The top volume, stem diameter, top length and root volume are all positively correlated with fifth-year height $(P<.001)$. However, these variables are also highly intercorrelated. For example, as root volume increases, the top volume increases but the top volume becomes proportionately larger than the root as the size of a normal, well balanced tree increases. Therefore, T/R is only meaningful as a subjective criterion on an individual tree basis, if at all. It is clear from the work of Mullin and Christl $(1981,1982)$ that the larger the tree the better the field performance in research plantings. Since larger trees have larger top-root ratios, large top-root ratios are not necessarily detrimental.

Another factor influencing the variation in $T / R$ is the quality and size of root obtained by current operational lifting practices in which rough handling or extreme adjustments to mechanical lifters can break off fibrous root-tips greatly increasing the $T / R$. By modifying these practices, the $T / R$ of nursery stock may be "adjusted" considerably.
The evidence suggests that $T / R$ has very limited value in nursery stock classification except possibly in the case of identifying damaged or deformed root systems. This situation is adequately covered through the use of root volume or root area index (Armson and Sadreika 1979) as an indicator of the morphological quality of roots while top volume or stem diameter are reasonable measures of morphological quality of the tops.

\section{References}

Armson, K.A. and R.D. Carman 1961. Forest tree nursery soil management. Ontario Dep. Lands Forests. $74 \mathrm{p}$.

Burdett, A.N. 1979. A non-destructive method for measuring the volume of intact plant parts. Can. J. Forest Res. 9:120-122.

Cannell, M.G.R. and S.C. Willett 1976. Shoot growth phenology, dry matter distribution and rootshoot ratios of provenances of Populus trichocarpa, Picea sitchensis and Pinus contorta growing in Scotland. Silvae Genetica 25(2): 49-59.

Cochran, W.G. 1977. Sampling techniques (Third edition). John Wiley and Sons, Toronto. $428 \mathrm{p}$.

Edgren, J.W. 1977. Field survival and growth of Douglas fir by age and size of nursery stock. USDA For. Serv. Res. Pap. PNW-217. $6 p$.

Glerum, C. and J.G. Boufford 1979. A comparison between top-root ratio determinations by oven-dry weight and volume displacement. Ontario Min. Natur. Resour., For. Res. Note 22, 4 p.

Hills, G.A. 1960. Regional site research. For. Chron. 36(4): 401-423

Hollander, M. and D.A. Wolfe 1973. Nonparametric statistical methods. John Wiley and Sons, Toronto. 503 p.

Mullin, R.E. 1976. Practical guidelines to nursery stock quality. Plantation Symposium, Kirkland Lake. Can. For. Serv., Great Lakes For. Res. Centre, Sault Ste. Marie, Ont. 1-11

Mullin, R.E. and C. Christl 1981. Morphological grading of white spruce nursery stock. For. Chron 57(3): 126-130.

Mullin, R.E. and C. Christl 1982. Morphological grading of white pine nursery stock. For. Chron 58(1): 40-43.

Mullin, R.E. and J. Svaton 1972. A grading study with white spruce nursery stock. Commonwealth For. Rev. 51(1):62-69.

Reese, K.H. and V. Sadreika 1979. Description of bare root shipping stock and cull stock. Ontario Min. Natur. Resour., 39 p.

Steel, R.G.D. and J.H. Torrie 1960. Principles and procedures of statistics. McGraw-Hill Book Co. Inc., Toronto. 481 p. 